Fourth International Symposium on Physics of Fluids (ISPF4)

International Journal of Modern Physics: Conference Series

Vol. 19 (2012) 166-172

(C) World Scientific Publishing Company

DOI: $10.1142 / \mathrm{S} 2010194512008707$

\title{
WIND TURBINE AERODYNAMICS PREDICTION USING FREE-WAKE METHOD IN AXIAL FLOW
}

\author{
MIN-SOO JEONG, SEUNG-JAE YOO AND IN LEE \\ Department of Aerospace Engineering, School of Mechanical Aerospace and System Engineering, \\ Korea Advanced Institute of Science and Technology (KAIST), Korea \\ Inlee@kaist.ac.kr
}

\begin{abstract}
Wind turbine aerodynamics remains a particularly challenging and crucial research for wind energy industry. The blade element momentum theory is the most widely used in predicting the performance of wind turbine, since the method is simple and fast numerical algorithm. The flow field generated by rotary wing is considerably important and complicated, however, the BEM method has some limitations to model the unsteady effects. To overcome these limitations, the aerodynamic analysis using a time-marching free-vortex wake method was performed in this paper. Moreover, the inboard region of the blade experience a delay in stall and enhanced values of the normal force coefficient because of rotational boundary layer augmentation and threedimensional effects. For this reason, Raj-Selig stall delay model was applied in this research. The numerical results were compared with experimental data, and the present results show excellent agreement with experiment.
\end{abstract}

Keywords: Free-vortex method; wake geometry; unsteady aerodynamics experiment.

\section{Introduction}

Wind turbine aerodynamics remains a particularly challenging and important research. Since aerodynamic or aeroelastic modeling should provide as a wind turbine design tool, a fast modeling is required. The minimal and robustness computing capacity requirements characterize the blade element momentum (BEM) theory as described by Glauert ${ }^{1}$, which is by far the most widely used model in aerodynamic codes today ${ }^{2}$. However, the BEM method has some limitations to model the three-dimensional effects, especially in the unsteady conditions of yawed flow. Other aerodynamic models exist, e.g. vortex method potential flow based on free-vortex wake method and prescribed wake method. These more advanced numerical models contain more physics and less empirical factor than BEM method ${ }^{2}$. The vortex method gives a more accurate and detailed wake description than simple aerodynamics such as BEM theory, and can be accurately used in unsteady conditions ${ }^{3}$. Furthermore, the computational cost of the vortex method is more expensive than the BEM, but still much more efficient than computational fluid dynamics (CFD) based on Euler and Navier-Stokes $(\mathrm{N}-\mathrm{S})$ equations ${ }^{4,5}$. For these reasons, the aerodynamic loads were computed using the vortex method based on a time-marching free-vortex wake method in this research. The wake geometry validation and aerodynamic responses were compared with Haans et al. experiment ${ }^{6}$ and unsteady 
aerodynamics experiment $(\mathrm{UAE})^{7}$ in axial flow condition. The numerical responses show excellent agreement with experiments ${ }^{6,7}$.

\section{Free-Vortex Wake Method for HAWT}

Unsteady wake of wind turbine blades is generated with the time-marching free-vortex wake method in this research. This modeling does not represent the ground boundary layer or the tower shadow. For describing shed and trailed vortex using vortex filaments, linear and curved vortex line were used. The movable velocities of the wake are the sum of the blade motions and the induced velocity from the wake. Here, induced velocities are computed using the Biot-Savart law with the Scully vortex core model ${ }^{8}$. To avoid infinite of the induced velocities around the core of a straight vortex line, that vortex core model was used. Kutta condition and the wake position for the wake generation can be expressed as follows ${ }^{9}$ :

$$
\begin{gathered}
\Gamma_{\text {wake }}=\Gamma_{\text {trailing edge }}, \\
(\Delta x, \Delta y, \Delta z)=\left(u(t)+u_{w}, v(t)+v_{w}, w(t)+w_{w}\right) \Delta t .
\end{gathered}
$$

Using the blade element theory (BET), the lift, drag, and pitch moment coefficients are obtained from airfoil table data. These aerodynamic coefficients of airfoil can be obtained from wind tunnel experiment and some commercial programs such as FLUENT. The normal and tangential force coefficients which are perpendicular and parallel to chord line can be defined as follows:

$$
\begin{aligned}
& C_{N}=c_{l} \cos \alpha+c_{d} \sin \alpha, \\
& C_{T}=c_{l} \sin \alpha-c_{d} \cos \alpha,
\end{aligned}
$$

where $\alpha$ is the effective angle of attack, $c_{l}$ and $c_{d}$ are the lift and drag coefficient. Furthermore, because of rotational boundary layer argumentation and three-dimensional effects, the inboard regions of the wind turbine blade experience a delay in stall and enhanced values of the normal force coefficient ${ }^{10}$. For this reason, various stall delay models have been developed. In this paper, stall-delay model by Raj-Selig ${ }^{11}$ was used to account for the enhanced values of $C_{N}$ in the post stall regime. The Raj-Selig stall delay models are approximately equal to that sum of two-dimensional airfoil table data and increment term in lift and drag.

$$
\begin{gathered}
c_{l, 3 D}=c_{l, 2 D}+\Delta c_{l}, \\
c_{d, 3 D}=c_{d, 2 D}+\Delta c_{d},
\end{gathered}
$$

where $\Delta c_{l}$ and $\Delta c_{d}$ are increments in the lift and drag coefficient and these increments can be expressed by:

$$
\Delta c_{l}=f_{l}\left(c_{l, p o t}-c_{l, 2 D}\right),
$$




$$
\Delta c_{d}=f_{d}\left(c_{d, p o t}-c_{d_{0}}\right)
$$

where $c_{l p o t}=2 \pi\left(\alpha-\alpha_{0}\right), c_{d_{0}}=c_{d_{2 D}}$ for $\alpha=0$, and the factors of $f_{l}$ and $f_{d}$ are given by

$$
\begin{aligned}
& f_{l}=\frac{1}{2 \pi}\left[\frac{1.6(c / r)}{0.1267} \frac{a-(c / r)^{\frac{d}{\lambda} \frac{R}{r}}}{b+(c / r)^{\frac{d}{\lambda} \frac{R}{r}}}\right]\left(1-\frac{r}{R}\right), \\
& f_{d}=\frac{1}{2 \pi}\left[\frac{1.6(c / r)}{0.1267} \frac{a-(c / r)^{\frac{d}{2 \lambda} \frac{R}{r}}}{b+(c / r)^{\frac{d}{2 \lambda} \frac{R}{r}}}\right]\left(2-\frac{r}{R}\right),
\end{aligned}
$$

where $a, b$, and $d$ are empirical correction factors and the constants $a, b$, and $d$ given as 1 by the author were used here.

\section{Results and Discussion}

Defining accurately the effective angle of attack for each blade section is obviously crucial to predicting the performance. The validation of the free-vortex wake method for a wind turbine in axial flow was performed against the wake geometry measurements obtained by Haans et $\mathrm{al}^{6}$. In addition, aerodynamic analysis of NREL Phase VI rotor ${ }^{7}$ was conducted. The ability of the free-vortex wake method to estimate the unsteady aerodynamic responses of wind turbine blades in a time-accurate manner was shown in this research.

\subsection{Wake Geometry Validation (Haans et al. Experiment)}

The tip vortex visualization experiment by Haans et al. ${ }^{6}$ was conducted in the Open Jet Facility of the Delft University of Technology (DUT). The open test section has a maximum attainable wind speed of $14.5 \mathrm{~m} / \mathrm{sec}$ and the wind speed in the open jet exit plane has been kept approximately constant at $5.5 \mathrm{~m} / \mathrm{sec}$. The rotor geometric properties in the experiment are described in Table 1.

Table 1. Geometric properties of the model scale wind turbine used by Haans et al. ${ }^{6}$

\begin{tabular}{lll}
\hline Number of blades & 2 blades & \\
Rotor radius & $0.6 \mathrm{~m}$ & \\
Root cut-out & $30 \%$ & \\
Blade twist & $6-6.67 \mathrm{r} / \mathrm{R} \quad$ for $\mathrm{r} / \mathrm{R} \leq 0.9$ \\
Airfoil section & 0 & for $\mathrm{r} / \mathrm{R} \geq 0.9$ \\
\hline
\end{tabular}

Numerical analyses were performed using the free-vortex wake method for the given geometric properties of turbine at various tip pitch angles $\left(\theta_{\text {tip }}=0^{\circ}, 2^{\circ}, 4^{\circ}\right)$ in axial flow 
condition. A numerical discretization of $\Delta \psi=\Delta \zeta=10^{\circ}$ of the free-vortex wake method was used in this research and this discretization gives a minor error in the reconstruction of the tip vortex induced velocity field ${ }^{10}$. The schematic side-view of the experimental setup and typical smoke-visualization showing tip vortex cores are shown in Fig. 1.

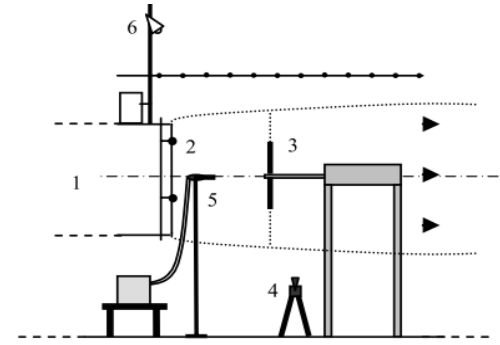

(a) Schematic of the experimental test setup

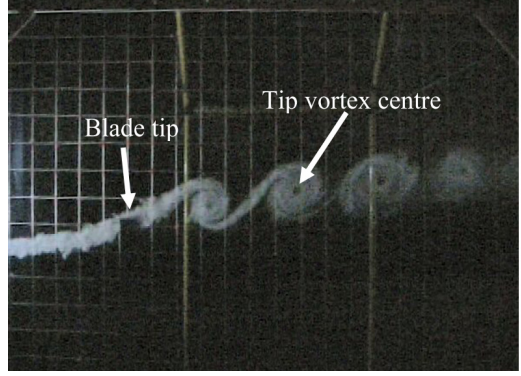

(b) Tip vortex for $\Lambda=0^{\circ}, \lambda=8$, and $\theta_{\text {tip }}=2^{\circ}$

Fig. 1. Schematic of the experimental test setup and flow visualization ${ }^{6,12}$.

Figure 2 shows a comparison between the numerical results from the free-vortex wake method and measured tip vortex locations obtained from the experiment for axial flow (unyawed) conditions for $\Lambda=0^{\circ}, \lambda=8$, and (a) $\theta_{\text {tip }}=0^{\circ}$, (b) $\theta_{\text {tip }}=2^{\circ}$, and (c) $\theta_{\text {tip }}=4^{\circ}$. For $\theta_{\text {tip }}=$ $0^{\circ}$ and $\theta_{\text {tip }}=2^{\circ}$, the estimated tip vortex positions are good agreement with experimental measurement. For $\theta_{\text {tip }}=4^{\circ}$, the wake expands behind the turbine and the simulation estimates the tip vortex positions well for younger wake, however, there are some differences in the tip vortex positions for older wake. The uncertainty in the tip vortex positions is increased because of the diffusion of flow particles.

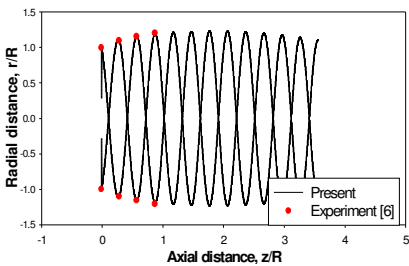

a) Tip vortex geometry for $\theta_{\text {tip }}=0^{\circ}$

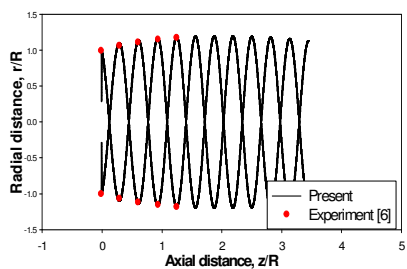

(b) Tip vortex geometry for $\theta_{\text {tip }}=2^{\circ}$

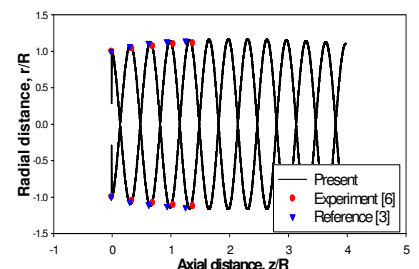

(c) Tip vortex geometry for $\theta_{\text {tip }}=4^{\circ}$

Fig. 2. Comparison of the tip vortex geometry.

\subsection{Aerodynamic analysis (Unsteady Aerodynamics Experiment)}

To compute aerodynamic loads, blade element theory was used in this paper. In other words, the induced velocities and local effective angle of attack was computed by freevortex wake method, then, the forces at each section are obtained from airfoil table data. These aerodynamic coefficients from airfoil table data can consider airfoil thickness and 
viscous effects. The aerodynamic results were compared with the unsteady aerodynamics experiment on the NREL Phase VI rotor in NASA Ames $80 \mathrm{ft}$. by $120 \mathrm{ft}$. (24 m by $36 \mathrm{~m}$ )

Table 2. Geometric properties of NREL Phase VI Rotor?

\begin{tabular}{ll}
\hline Rating & $19.8 \mathrm{~kW}$ \\
Number of blades & 2 blades \\
Rotational direction & Upwind, CCW \\
Rotor radius & $5.029 \mathrm{~m}$ \\
Blade tip pitch & 3 degree \\
Airfoil section & $\mathrm{S} 809$
\end{tabular}

wind tunnel. The geometric properties of NREL Phase VI rotor are presented in Table 2. The rotational speed of NREL Phase VI rotor is a constant speed, $72 \mathrm{rpm}$. In this case, the blade is assumed to be sufficiently rigid to ignore the elastic deflections, thus, the structural characteristics were not considered. The analysis was performed with the 30 span-wise by 3 chord-wise mesh, and a numerical discretization of $\Delta \psi=\Delta \zeta=10^{\circ}$ was applied for the comparison with prediction. Comparisons with this research were focused on measured normal and tangential force coefficients which are perpendicular and parallel to airfoil chord line. The results of the aerodynamic force coefficients at five span-wise stations, i.e. $\mathrm{r} / \mathrm{R}=0.30,0.47,0.63,0.80,0.95$ were derived from 22 pressure taps per station ${ }^{7}$.

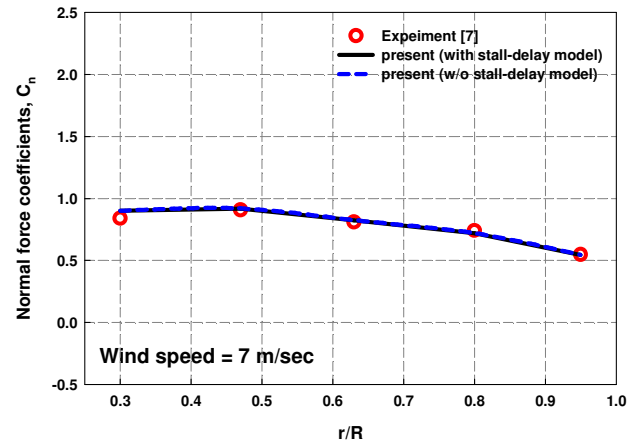

Normal force coefficient, $C_{n}$

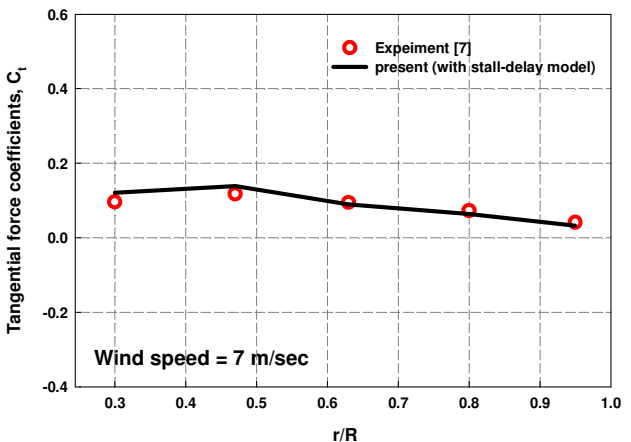

(a) Tangential force coefficient, $C_{t}$

Fig. 3. Aerodynamic force coefficients at wind speed $7 \mathrm{~m} / \mathrm{sec}$.

The aerodynamic analyses were performed at wind speed $7 \mathrm{~m} / \mathrm{sec}$ and $13 \mathrm{~m} / \mathrm{sec}$. These predictions using the free-vortex wake method were compared with experimental data and are shown in Figs. 3 and 4. At wind speed $7 \mathrm{~m} / \mathrm{sec}$, the flow condition is attached along the blade, and the aerodynamic results show the numerical and experimental results in excellent agreement. For the detached flow case (wind speed $>9 \mathrm{~m} / \mathrm{sec}^{13}$ ), aerodynamic coefficients were corrected by the Raj-Selig stall delay model. In Fig. 4, the normal force coefficient at $13 \mathrm{~m} / \mathrm{sec}$ produces an underprediction inboard of the spanwise station of 0.80 . In the case of tangential force coefficient, the use of Raj-Selig stall 
delay model caused an overprediction over at least the inboard half of the blade, and a small under prediction is seen near the blade tip. In conclusion, the overall estimated values of normal and tangential force coefficients are mostly in good agreement with the experiment ${ }^{7}$.

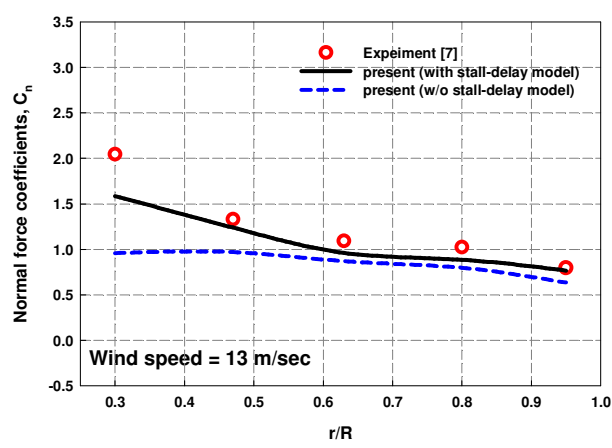

Normal force coefficient, $C_{n}$

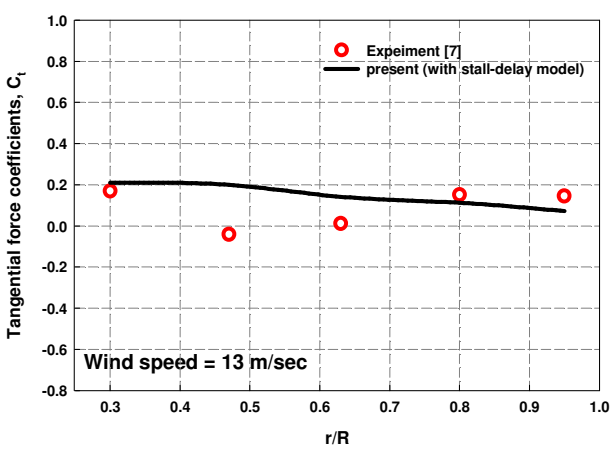

(a) Tangential force coefficient, $C_{t}$

Fig. 4. Aerodynamic force coefficients at wind speed $13 \mathrm{~m} / \mathrm{sec}$.

\section{Conclusions}

The verification and validation of free-vortex wake model for wind turbine blades were investigated. Through the wake geometry validation, the predicted tip vortex positions were found to be in good agreement with Haans et al. experimental measurement. The present aerodynamic responses of NREL Phase VI rotor are in good agreement with unsteady aerodynamics experiment.

\section{Acknowledgments}

This work was supported by the New \& Renewable Energy of Korea Institute of Energy Technology Evaluation and Planning (KETEP) grant funded by the Korea government Ministry of Knowledge Economy (2009T100100253) and also supported by WCU (World Class University) program through the National Research Foundation of Korea funded by the Ministry of Education, Science and Technology (R31-2008-000-10045-0). The authors are grateful for their support.

\section{References}

1. H. Glauert, Airplane Propellers, Dover Publications, New York, 1963.

2. F. Rasmussen, M. H. Hansen, K. Thomsen, and et al., Wind Energy, 6, 213 (2003).

3. S. Gupta and J. G. Leishman, in Proc. 24th ASMW Wind Energy Symp. Reno, 2005.

4. M. O. L. Hansen, J. N. Sørensen, S. Voutsinas, and et al., Prog. Aero. Sci., 42, 285-330 (2006).

5. J. G. Leishman, Wind Energy, 5, 85 (2002).

6. W. Haans, T. Sant, G. Kuik, and G. Van Bussel, in Proc. 24th ASMW Wind Energy Symp. Reno, 2005. 
7. M. M. Hand, D. A. Simms, L. J. Fingersh, and et al., NREL/TP-500-29955, 2001.

8. M. P. Scully, MIT ASRL TR 178-1, 1975.

9. S. U. Na, Ph.D. Dissertation, Dept. of Aerospace Eng., KAIST, Korea, 1998.

10. S. Gupta, Ph.D. Dissertation, Dept. of Aerospace Eng., University of Maryland, U. S., 2006.

11. N. V. Raj, Master Thesis, University of Illinois at Urbana Champaign, U.S., 2000.

12. W. Haans, T. Sant, G. Van Kuik and G. Van Bussel, AIAA Paper, 2005-590, 2005.

13. T. Sant, G. Kuik and G. J. W. Bussel, Wind Energy, 9, 549 (2006). 